\title{
Assessment of Antibiotic Prescription Pattern as a Predisposing Factor to Growing Antibiotics Resistance in Kwara South Senatorial District of Nigeria
}

\author{
Gbenga Solomon Joseph ${ }^{1 *}$, Adekunle Ganiyu Salaudeen ${ }^{2}$ \\ ${ }^{1}$ School of Public Health, Texila American University, Georgetown, Guyana, South America \\ ${ }^{2}$ Department of Epidemiology and Community Health, University of Ilorin Teaching \\ Hospital, Ilorin, Nigeria
}

\begin{abstract}
The most prescribed medicines in the health facilities are antibiotics, and their unethical prescription and empirical use are factors that promote irrational use and the spread of antibiotics resistance. The objective of this study was to assess antibiotic prescription patterns as a predisposing factor to antibiotics resistance in Kwara south senatorial district of Nigeria. A cross-sectional study was carried out from September 2020 to January 2021 in 4 randomly selected Government and Private hospitals. The WHO questionnaire on antibiotic resistance prevalence survey was modified and administered to 442 patients on antibiotics to collect data, and IBM/SPSS version 23 was used for analysis. A total of 891 antibiotics were prescribed in 442 prescriptions. The average number of antibiotics per prescription was approximately 2.0. Metronidazole (44.6\%) was the most prescribed antibiotics, followed by Ceftriaxone (41\%), and Gastro-intestinal tract infection was most (17,6\%) common indication. Irrational prescribing accounted for $22.4 \%$ and most of the antibiotics prescribed were in the watch group of WHO categorization with high potential for resistance. Prescription in trade name was $57.9 \%$. Parenteral route (54.8\%) was most reported route of administration. The most common treatment type was empirical treatment (83.3\%). Association between age and empirical treatment type was statistically significant with p-value of 0.02. Empirical treatment occurred in infant and young child irrespective of the gender of child. There was irrational use of antibiotics in secondary care facilities in this study. Antibiotic stewardship program is recommended for secondary health care facilities in Kwara senatorial district.
\end{abstract}

Keywords: Antibiotics resistance, Irrational use, Prescription.

\section{Introduction}

An antibiotic is a type of antimicrobial substance active against bacteria. It is the most important type of antibacterial agent for fighting bacterial infections. Antibiotics medications are widely used in the treatment and prevention of bacterial infections. They may either kill or inhibit the growth of bacteria. Currently, antibiotics are the most prescribed medicines in the hospital worldwide [1]. Antibiotic resistance occurs when bacteria change in response to the use of these medicines. Bacteria, not humans or animals, become antibiotic-resistant [2].

Prescription patterns are the extent and profile of drug use, trends, quality of drugs, and compliance with regional, state, or national guidelines like standard treatment guidelines, usage of drugs from essential medicine list, and use of generic drugs. Inappropriate prescriptions promote the inappropriate use of antibiotics; this has resulted in antibiotics resistance in communities in developing countries. This has 
increased resistance to first-line antibiotics and promote the use of second-line antibiotics, which have high resistance potential in the community [3].

According to the study carried out on antimicrobial resistance in 2015, the researcher observed that the lack of new discovery of antibiotics and inappropriate use of existing antibiotics contribute to increasing bacteria resistance. The inappropriate use of antibiotics is one of the threats to global health [4]. He further observed that antibiotic is often used without any prescription. The researcher said, the use, overuse, and misuse of antibiotics promote resistance in numerous species of bacteria, lead to loss of clinical and economic outcomes of the antibiotic's treatment [4]. In a study in Spain, out of the cases given antibiotics in primary health care, $69.9 \%$ did not require antibiotic treatment. The global clinical inappropriateness in the use of antibiotics amounted to $43.7 \%$ [5].

In a study in Benin city, Nigeria, inappropriate use of antibiotics was about $56.9 \%$, and patients took incomplete regimens when prescribed by doctors or other health professionals [6]. Inappropriate use of antibiotics promotes the risk for selection and spread of antibiotic-resistant bacteria [7]. In a developing country, qualified health personnel are scarce and cannot serve the entire population, even in the urban community, especially in hospitals with a high patient load. This has led to task sharing, contributing greatly to the inappropriate use of antibiotics [7].

In low resource setting, the factors that contribute to antimicrobial resistance epidemic are unique, the triple threat of unfettered access, minimal product regulation and failure to ensure appropriate guideline on antibiotic prescription is followed, and lack of clinical diagnostic tools to support antibiotic resistance control [8]. To optimize the use of antimicrobials and to pave the way for the implementation of antibiotic stewardship in the hospital. The World Health Organization (WHO) in 2017 updated the Essential Medicine List (EML) and categorized antibiotics into three groups- Access, Watch and Reserve (AWaRe). The change aims to ensure that antibiotics are available when needed and that the appropriate antibiotics are prescribed for the right infections. This would improve treatment outcomes, reduce the development of drug-resistant bacteria, and preserve the effectiveness of "last resort" antibiotics that are needed when all others failed [9].

The Access group antibiotics are the first and second choices for empirical treatment of 21 common clinical syndromes. The first choice is narrow-spectrum agents, whereas the second choice is broad-spectrum agents with higher resistance potential. Antibiotics such as amoxicillin/ampicillin, benzathine penicillin, trimethoprim-sulfamethoxazole, amoxicillinclavulanic acid, cloxacillin are first-choice agents. The Watch group includes antibiotics with high resistance potential when compared with the Access group and includes antibiotics such as third-generation cephalosporins, fluoroquinolones, and carbapenems. The Reserve group includes antibiotics of last resort like polymyxins, fourth and fifth-generation cephalosporins. WHO recommends that the Access group of antibiotics be widely available and affordable and minimize the use of the other two groups of antibiotics [9].

Appropriate therapy is meant the use of antibiotics to which the organism cultured from the patient is susceptible, as determined by in vitro tests. In study carried out in intensive care unit of the hospital on the empirical Antibiotic Preference for the critically sick person. The author reviewed these three strategies, namely discontinuation or streamlining of empirical therapy when culture results are available, withdraw certain antibiotic classes (broadspectrum antibiotics), and employed antibiotic cycling. These are commonly practiced strategies to reduce the risk of empirical therapy while ensuring that empirical therapy is effective. The author observed that mortality was high when empirical therapy is not targeting causative organisms. Probably due to limitations 
of current clinical and diagnostic methods in most hospitals, this led to given empirical therapy to the patient that is not infected or has noninfectious causes for their clinical symptom. The best way to promote effective empirical treatment in the hospital is to promote appropriate prescription and antibiotics use through evaluation of antibiotic use [10].

Despite the huge problem of inappropriate prescriptions and antibiotic resistance, there is a scarcity of research and data on this subject in resource-limited settings. Therefore, this study set out to examine antibiotic prescription patterns as a predisposing factor to growing antibiotics resistance in selected Private and Government Hospitals in Kwara south senatorial district of Nigeria.

\section{Materials and Methods}

A cross-sectional study to assess antibiotics prescription in Kwara south senatorial district was carried out on a total of 442 patients between September 2020 to January 2021. Approval from the State Ministry of Health Research and Ethical Committee was obtained prior to the commencement of the study. A multistage sampling technique was used. Out of three senatorial districts in Kwara State, Kwara South senatorial district was selected using simple random sampling by balloting. The list of the Government secondary health facility and Private secondary health facility located in Kwara senatorial was obtained from the State Ministry of Health and used as the sampling frame. Two hospitals from Government and private hospital were selected from the list of Government and private hospitals using simple random sampling. Using eligibility criteria, hospital patient registers from private and secondary health facilities selected were screened to have a list of eligible respondents for the sampling frame for this study. Systematic Sampling techniques to select respondents. The first respondent was selected by simple random sampling, while the subsequent respondents were selected using sampling interval. A proportionate sampling method was used to determine the number of respondents from private and Government health facilities using the patient load in the four selected health hospitals.

WHO questionnaire on antibiotic resistance prevalence survey was modified and adapted to collect data regarding the socio-demographic data of the respondents, and antibiotic prescription patterns were collected included both out-patients (OP) and in-patients (IP). The validity and reliability of the data tool were done. The WHO modified instrument was pre-tested with the in-patient and out-patients in the central geopolitical zone- Ilorin west LGA. The purpose was to identify gaps, improve the tool and ensure consistency in answering between respondents, after getting written informed consent from the subjects. Other relevant data was obtained from the patient's case sheet. All data were tabulated and analyzed. Descriptive and inferential statistics were used for analysis, and the results were expressed.

\section{Description of the Study Area}

This study was conducted in Kwara South Senatorial District (KSSD) of Kwara State. The Language of the people of Kwara south senatorial district is mainly Yoruba, with three sub-ethnic nationalities, namely, Ekiti, Ibollo, and Igbomina. There are other ethnic groups like Bassa, Fulani, Hausa, Igbo, Nupe, and Tiv living in the area. Kwara south senatorial district has guinea savannah vegetation. This senatorial district geographically shared boundaries with Kwara central senatorial district to the west, Kwara north senatorial district to the North, Kogi State to the east, and with the duo of Ekiti and the Osun States to the South.

The levels of care in the public sector are primary, secondary. The primary level is financed and managed by the local government, the secondary by the state. Primary health care (PHC) facilities exist at all the Local Government Areas (LGAs). They form the entry point of the community into the health care 
system. PHC facilities provide preventive, curative, promotive, and pre-referral care to the population. PHC facilities are typically staffed by nurses, community health workers, community health extension workers (CHEWs), junior CHEWs, and environmental health officers. They are headed technically and administratively by the PHC coordinator, normally the Medical Officer of Health (MOH) where one exists who is assisted by program officers and unit heads.

The secondary health facilities referred to as general hospitals provide medical and laboratory services, as well as specialized health services such as surgery, pediatrics, obstetrics, and gynecology to patients referred from the PHC level. Medical officers, nurses, midwives, pharmacists, laboratory specialists, and community health officers are the typical staff at secondary health facilities. They are headed by Medical Directors.
The study was conducted in four secondary health facilities: General Hospital Omu-Aran and General Hospital Offa (public health facilities) and Private Hospital are E-Square Hospital, Oro and Olalomi Hospital, Erin-ile. These health facilities are located in four LGAs of the seven LGAs in the senatorial district.

\section{Results}

\section{Socio-demographic Characteristics of Participants}

The mean age of the respondents was $33.04 \pm$ 21.54 years. One hundred and sixty-three respondents were males, and 273 were females. The married respondents accounted for $55.6 \%$ of the respondents. The majority of the respondents were a student (33.7\%). Respondents with tertiary education accounted for 194 (43.9\%). The average monthly income was 30,000 naira $(29,000)$.

Table 1. Socio-demographic Characteristics of Participants

\begin{tabular}{|l|l|l|}
\hline \multicolumn{2}{|l|}{ Variable } & \multicolumn{2}{l|}{} \\
\hline Age (years) & 82 & 18.6 \\
\hline $1-12$ & 28 & 6.3 \\
\hline $13-18$ & 267 & 60.4 \\
\hline $19-59$ & 65 & 14.7 \\
\hline$\geq 60$ & $33.04 \pm 21.34$ \\
\hline Mean \pm SD & $30.00(29,000)$ & \\
\hline Median (IQR) & $1-90$ & \\
\hline Range & \multicolumn{2}{l|}{} \\
\hline Gender & 163 & 36.9 \\
\hline Male & 279 & 63.1 \\
\hline Female & \multicolumn{2}{l|}{} \\
\hline Marital status & 176 & 39.8 \\
\hline Single & 246 & 55.7 \\
\hline Married & 3 & 0.7 \\
\hline Divorced & 17 & 3.8 \\
\hline Widowed & \multicolumn{2}{|l}{} \\
\hline Religion & 223 & 50.5 \\
\hline Islam & 217 & 49.1 \\
\hline Christianity & 2 & 0.4 \\
\hline Traditional & & \\
\hline Educational status & \multicolumn{2}{l}{} \\
\hline
\end{tabular}




\begin{tabular}{|l|l|l|}
\hline Primary & 74 & 16.7 \\
\hline Secondary & 109 & 24.7 \\
\hline Tertiary & 194 & 43.9 \\
\hline Arabic & 5 & 15.6 \\
\hline Occupation & \multicolumn{2}{l|}{} \\
\hline Pupil/ Student & 149 & 33.7 \\
\hline Artisan & 20 & 4.5 \\
\hline Trader/ Farmer & 136 & 30.8 \\
\hline Civil servant/ Professional & 77 & 17.4 \\
\hline Others & 13 & 2.9 \\
\hline Retired/ Unemployed & 22 & 5.0 \\
\hline Not applicable why or *under aged & 25 & 5.7 \\
\hline Average income & \multicolumn{2}{|l}{} \\
\hline Average income per month & $30,000(18,000-47,000)$ \\
\hline Range & $1,000-100,000$ & \\
\hline
\end{tabular}

Of the 442 participants, 371 were in-patients, and 71 were out-patients. About a fifth of the participants $(17 \%)$ were surgical patients. Four of every ten patients (43.4\%) had peripheral catheter, while $14.9 \%$ had undergone urinary catheterization on admission. Less than a tenth $(4.8 \%)$ of the in-patients had been intubated.

Table 2. Patient Medical Characteristics

\begin{tabular}{|l|l|l|}
\hline Variable & Frequency $(\mathbf{n}=\mathbf{4 4 2})$ & Percent $(\%)$ \\
\hline Patient care type & 83.9 \\
\hline In-patient & 371 & 16.1 \\
\hline Out-patient & 71 & 17.0 \\
\hline Surgery since admission $(\mathbf{n}=\mathbf{3 7 1})$ \\
\hline Yes & 63 & 83.0 \\
\hline No & 308 & 1.4 \\
\hline Central vascular catheter & 98.6 \\
\hline Yes & 6 & \\
\hline No & 436 & 43.4 \\
\hline Peripheral & 192 & 56.6 \\
\hline Yes & 250 & 14.9 \\
\hline No & 66 & 85.1 \\
\hline Urinary catheter & \\
\hline Yes & 376 & 4.8 \\
\hline No & 21 & 95.2 \\
\hline Intubation & 421 & \\
\hline Yes & \\
\hline No &
\end{tabular}

More prescription was made in trade name $(57.9 \%)$ compare with a generic name $(42.1 \%)$. The parenteral route $(54.8 \%)$ was the most reported route of administration, and intravenous was the highest reported parenteral route of administration. Non-specialist physician has 
more percentage $(56.8 \%)$ of prescription than specialist physicians $(38.2 \%)$. Compliance with prescription guidelines cannot be assessed in the majority $(59.3 \%)$ of reported cases, while the majority of the treatment examined were empirical treatment $(83.3 \%)$ as against directed treatment $(16.7 \%)$.

Table 3. Prescription Pattern of Antibiotics in Selected Hospital of Kwara South Senatorial District

\begin{tabular}{|l|l|l|}
\hline Variable & Frequency & Percent \\
\hline Name of antibiotic prescribed & 186 & 42.1 \\
\hline Generic name & 256 & 57.9 \\
\hline Trade name & 242 & 54.8 \\
\hline Route of administration & 124 & 28.1 \\
\hline Parenteral alone & 73 & 16.5 \\
\hline Oral alone & 3 & 0.6 \\
\hline Parenteral with oral & \multicolumn{2}{|l|}{} \\
\hline Inhalational & 100 & 41.3 \\
\hline Oral switch if parenteral alone (n= 242) \\
\hline Yes & 142 & 58.7 \\
\hline No & 11 & 3.5 \\
\hline Parenteral type & 300 & 96.2 \\
\hline Intramuscular & 1 & 0.3 \\
\hline Intravenous & \multicolumn{2}{|l}{} \\
\hline Subcutaneous & 169 & 38.2 \\
\hline Prescriber & 251 & 56.8 \\
\hline Specialist physician & 1 & 0.2 \\
\hline Non specialist physician & 21 & 4.8 \\
\hline Other & 143 & 32.4 \\
\hline Unknown & 12 & 2.7 \\
\hline Compliance with guideline & 59.3 \\
\hline Yes & 262 & 5.7 \\
\hline No & 25 & 16.7 \\
\hline Not assessable & 83.3 \\
\hline No information & 368 \\
\hline Treatment type & \multicolumn{2}{|l}{} \\
\hline Directed treatment & \multicolumn{2}{|l|}{} \\
\hline Empirical treatment & \multicolumn{2}{|l|}{} \\
\hline \multicolumn{4}{|l|}{} \\
\hline
\end{tabular}

In $90 \%$ of cases, indications for antibiotic prescription were reported. The gastro-intestinal tract was most $(17,6 \%)$ common, followed by respiratory tract infection $(17.1 \%)$, while the least reported indication was neurological infections (1.3\%). Community-acquired infection $(75.6 \%)$ was the most reported source of infection, and the least reported was hospitalacquired infection (1\%). In $77.6 \%$ of reported cases, the use of antibiotics was justified. 
Table 4. Indication for Antibiotics use among Respondents.

\begin{tabular}{|c|c|c|}
\hline Variable & Frequency $(n=442)$ & Percent \\
\hline \multicolumn{3}{|c|}{ Reason/ indication for prescription stated } \\
\hline Yes & 398 & 90.0 \\
\hline No & 44 & 10.0 \\
\hline \multicolumn{3}{|l|}{ Indication $(\mathrm{n}=398)$} \\
\hline Gastro-intestinal & 70 & 17.6 \\
\hline Respiratory & 68 & 17.1 \\
\hline Urogenital & 51 & 12.8 \\
\hline Musculoskeletal & 14 & 3.5 \\
\hline Oral & 8 & 2.0 \\
\hline Obstetrics & 42 & 10.6 \\
\hline Fever (unknown origin) & 40 & 10.1 \\
\hline Sepsis (unknown focus) & 31 & 7.8 \\
\hline Ear infection/ discharge & 20 & 5.0 \\
\hline Neurological & 5 & 1.3 \\
\hline Others & 49 & 12.3 \\
\hline \multicolumn{3}{|l|}{ Indication type $(n=398)$} \\
\hline Hospital associated infection & 4 & 1.0 \\
\hline Community acquired infection & 301 & 75.6 \\
\hline Surgical prophylaxis & 52 & 13.1 \\
\hline Medical prophylaxis & 17 & 4.3 \\
\hline Other & 24 & 6.0 \\
\hline \multicolumn{3}{|c|}{ Indication for use of antibiotics $(n=398)$} \\
\hline Use justified & 309 & 77.6 \\
\hline Inappropriate prescription & 89 & 22.4 \\
\hline
\end{tabular}

Gynaecology and Obstetrics surgery accounted for more than two-thirds (69.2\%) of surgical prophylaxis distantly, followed by GIT surgery with $21.2 \%$. Multiple doses of surgical antibiotic prophylaxis for over 24 hours were more $(69.2 \%)$ reported comparing with multiple doses less than 24 hours (19.2\%) or single-dose prophylaxis $(11.5 \%)$.

Table 5. Pattern of Antibiotics use for Surgical Prophylaxis in Health Facilities of Kwara South Senatorial District

\begin{tabular}{|c|c|c|}
\hline Variable & Frequency $(\mathrm{n}=52)$ & Percent \\
\hline \multicolumn{3}{|l|}{ Site of surgical prophylaxis } \\
\hline Gastrointestinal tract & 11 & 21.2 \\
\hline Skin, soft tissue, bone and joint & 1 & 1.9 \\
\hline Urinary tract & 4 & 7.7 \\
\hline Gynaecology and Obstetrics & 36 & 69.2 \\
\hline \multicolumn{3}{|l|}{ Doses of surgical prophylaxis } \\
\hline One dose administered to the patient & 6 & 11.5 \\
\hline Multiple doses administered to the patient within 24 hours & 10 & 19.2 \\
\hline Multiple doses administered to the patient for a duration $>24$ hours & 36 & 69.2 \\
\hline
\end{tabular}


Commonly prescribed antibiotics in order of frequency was presented in this table, with metronidazole having the highest frequency 197 (44.6\%), followed by Ceftriaxone 181(41\%), ciprofloxacin 151(34.2\%), Gentamicin 24.2\%, and Amoxicillin clavulanic acid $18.6 \%$, while penicillin and ceftazidime had the least $1(1 \%)$.

Table 6. Commonly Prescribed Antibiotics in the Study Area

\begin{tabular}{|l|l|l|}
\hline Name of antibiotics & Number of prescriptions (n=442) & Percent \\
\hline Metronidazole & 197 & 44.6 \\
\hline Ceftriaxone & 181 & 41.0 \\
\hline Ciprofloxacin & 151 & 34.2 \\
\hline Gentamicin & 107 & 24.2 \\
\hline Amoxicillin clavulanic acid & 82 & 18.6 \\
\hline Ofloxacin & 35 & 7.9 \\
\hline Amoxicillin & 34 & 7.7 \\
\hline Cefuroxime & 18 & 4.1 \\
\hline Levofloxacin & 10 & 2.3 \\
\hline Erythromycin & 7 & 1.6 \\
\hline Doxycycline & 6 & 1.4 \\
\hline Nitrofurantoin & 6 & 1.4 \\
\hline Streptomycin & 6 & 1.4 \\
\hline Trimethoprim- Sulfamethoxazole & 6 & 1.4 \\
\hline Azithromycin & 5 & 1.1 \\
\hline Ampicillin cloxacillin & 3 & 0.7 \\
\hline Cefixime & 3 & 0.7 \\
\hline Clarithromycin & 2 & 0.5 \\
\hline Ceftazidime & 1 & 0.2 \\
\hline Penicillin & 1 & 0.2 \\
\hline & & \\
\hline
\end{tabular}

Association between age and empirical treatment type was statistically significant with a $\mathrm{p}$-value of 0.02 . While there was no statistically

treatment type. Empirical treatment was mostly used for infants and young child irrespective of the gender of the child. significant difference between gender and

Table 7. Association between Treatment Type, Age, and Sex of the Patients

\begin{tabular}{|l|l|l|l|l|l|}
\hline \multirow{3}{*}{ Variable } & \multicolumn{2}{|l|}{ Treatment type } & \multirow{2}{*}{ Total } & \multirow{2}{*}{$\boldsymbol{\chi}^{\mathbf{2}}$} & \multirow{2}{*}{-value } \\
\cline { 2 - 4 } & Directed & Empirical & & & \\
\cline { 2 - 4 } & $\mathbf{n}(\boldsymbol{\%})$ & $\mathbf{n}(\boldsymbol{\%})$ & $\mathbf{N}(\%)$ & & \\
\hline Age & $5(6.1)$ & $77(93.9)$ & 82 & \multirow{2}{*}{9.821} & $\mathbf{0 . 0 2 0}$ \\
\hline $13-18$ & $6(21.4)$ & $22(78.6)$ & 28 & & \\
\hline $19-59$ & $54(20.2)$ & $213(79.8)$ & 267 & & \\
\hline$\geq 60$ & $9(13.8)$ & $56(86.2)$ & 65 & & \\
\hline Gender & & & & \\
\hline Male & $26(16.0)$ & $137(84.0)$ & 163 & 0.116 & 0.733 \\
\hline Female & $48(17.2)$ & $231(82.8)$ & 279 & & \\
\hline
\end{tabular}

$\chi^{2}$ : Chi square test; $*$ : $p$ value $<0.05$ 
There was more directed treatment in private health facilities compared with the public. The observed relationship between the type of hospital and treatment type was statistically significant $(\mathrm{p}<0,001)$. While hospital type and patient's characteristics with respect to inpatient or out-patient were not statistically significant.

Table 8. Association between Treatment Type, Hospital Facility and Patient Characteristics

\begin{tabular}{|c|c|c|c|c|c|}
\hline \multirow[t]{3}{*}{ Variable } & \multicolumn{2}{|c|}{ Treatment type } & \multirow[t]{2}{*}{ Total } & \multirow[t]{3}{*}{$\chi^{2}$} & \multirow[t]{3}{*}{$p$-value } \\
\hline & Directed & Empirical & & & \\
\hline & n (\%) & $\mathrm{n}(\%)$ & $\mathbf{N}(\%)$ & & \\
\hline \multicolumn{6}{|c|}{ Type of facility } \\
\hline Private & $45(33.6)$ & $89(66.4)$ & 134 & \multirow[t]{2}{*}{39.122} & \multirow[t]{2}{*}{$<0.001$} \\
\hline Public & $29(9.4)$ & $279(90.6)$ & 308 & & \\
\hline \multicolumn{6}{|c|}{ In outpatient } \\
\hline Inpatient & $58(15.6)$ & $313(84.4)$ & 371 & \multirow[t]{2}{*}{2.037} & \multirow[t]{2}{*}{0.154} \\
\hline Outpatient & $16(22.5)$ & $55(77.5)$ & 71 & & \\
\hline
\end{tabular}

$\chi^{2}$ : Chi square test; F: Fisher's exact test; *: $p$ value $<0.05$

The most used treatment type for prophylaxis is empirical. The use of prophylaxis by empirical treatment type was statistically significant $(p<0.001)$, while the association between a possible source of infection and empirical treatment type was not statistically significant $(\mathrm{p}=0.332)$.

Table 9. Association between Treatment Type and Indication for Antibiotic Therapy

\begin{tabular}{|c|c|c|c|c|c|}
\hline \multirow[t]{3}{*}{ Variable } & \multicolumn{2}{|c|}{ Treatment type } & \multirow[t]{2}{*}{ Total } & \multirow[t]{3}{*}{$\chi^{2}$} & \multirow[t]{3}{*}{$p$-value } \\
\hline & \multirow{2}{*}{$\begin{array}{l}\text { Directed } \\
\mathrm{n}(\%) \\
\end{array}$} & \multirow{2}{*}{$\begin{array}{l}\text { Empirical } \\
\text { n (\%) }\end{array}$} & & & \\
\hline & & & $\mathbf{N}(\%)$ & & \\
\hline \multicolumn{6}{|l|}{ Indication } \\
\hline Gastrointestinal & $3(4.3)$ & $67(95.7)$ & 70 & \multirow[t]{11}{*}{$70.058^{F}$} & \multirow[t]{11}{*}{$<0.001 *$} \\
\hline Respiratory & $1(1.5)$ & $67(98.5)$ & 68 & & \\
\hline Urogenital & $18(35.3)$ & $33(64.7)$ & 51 & & \\
\hline Musculoskeletal & $3(21.4)$ & $11(78.6)$ & 14 & & \\
\hline Oral & $1(12.5)$ & $7(87.5)$ & 8 & & \\
\hline Obstetrics & $4(9.5)$ & $38(90.5)$ & 42 & & \\
\hline Fever (unknown origin) & $1(2.5)$ & $39(97.5)$ & 40 & & \\
\hline Sepsis (unknown focus) & $4(12.9)$ & $27(87.1)$ & 31 & & \\
\hline Ear infection/ discharge & $11(55.0)$ & $9(45.0)$ & 20 & & \\
\hline Neurological & $0(0.0)$ & $5(100.0)$ & 5 & & \\
\hline Others & $8(16.3)$ & $41(83.7)$ & 49 & & \\
\hline \multicolumn{6}{|l|}{ Source of Infection } \\
\hline Hospital associated infection & $1(25.0)$ & $3(75.0)$ & 4 & \multirow[t]{5}{*}{$4.299^{\mathrm{F}}$} & \multirow[t]{5}{*}{0.332} \\
\hline Community acquired infection & $43(14.3)$ & $258(85.7)$ & 301 & & \\
\hline Surgical prophylaxis & $4(7.7)$ & $48(92.3)$ & 52 & & \\
\hline Medical prophylaxis & $1(5.9)$ & $16(94.1)$ & 17 & & \\
\hline Other & $5(20.8)$ & $19(79.2)$ & 24 & & \\
\hline
\end{tabular}

$\chi^{2}$ : Chi square test; F: Fisher's exact test; $*: p$ value $<0.05$ 
More antibiotics prescribed for empirical 144 (77.4\%), the oral route of administration 100 (80.6\%), physician-prescribed antibiotics for empirical treatment $116(68.6 \%)$ compared to direct treatment. Type. Association between the pattern of prescription as described by a number of antibiotics prescribed $\quad(\mathrm{p}<0.003)$, administration route ( $\mathrm{p}<0.001)$, a name by which antibiotic are prescribed $(\mathrm{p}<0.005)$, oral switch ( $p>0.001)$, a cadre of healthcare workers prescribing antibiotic $(p>0.001)$ and compliance with the guideline for antibiotics prescription ( $>0.001)$ and treatment type are statistically significant.

Table 10. Association between Treatment Type and other Pattern of Antibiotic Prescription

\begin{tabular}{|c|c|c|c|c|c|}
\hline \multirow[t]{3}{*}{ Variable } & \multicolumn{2}{|c|}{ Treatment type } & \multirow[t]{2}{*}{ Total } & \multirow[t]{3}{*}{$\chi^{2}$} & \multirow[t]{3}{*}{$p$-value } \\
\hline & \multirow{2}{*}{\begin{tabular}{|l|} 
Directed \\
$\mathrm{n}(\%)$ \\
\end{tabular}} & \multirow{2}{*}{$\begin{array}{l}\text { Empirical } \\
\mathrm{n}(\%) \\
\end{array}$} & & & \\
\hline & & & $\mathbf{N}(\%)$ & & \\
\hline \multicolumn{6}{|c|}{ Number antibiotics prescribed } \\
\hline 1 & $19(10.1)$ & $169(89.9)$ & 188 & \multirow[t]{4}{*}{14.157} & \multirow[t]{4}{*}{$0.003 *$} \\
\hline 2 & $19(17.10029$ & $92(82.9)$ & 111 & & \\
\hline 3 & $32(26.4)$ & $89(73.6)$ & 121 & & \\
\hline 4 & $4(18.2)$ & $18(81.8)$ & 22 & & \\
\hline \multicolumn{6}{|c|}{ Name of antibiotics prescribed } \\
\hline Generic name & $42(22.6)$ & $144(77.4)$ & 186 & \multirow[t]{2}{*}{7.854} & \multirow[t]{2}{*}{$0.005^{*}$} \\
\hline Trade name & $32(12.5)$ & $224(87.5)$ & 256 & & \\
\hline \multicolumn{6}{|c|}{ Administration route } \\
\hline Oral & $24(19.4)$ & $100(80.6)$ & 124 & \multirow[t]{4}{*}{$43.897^{\mathrm{F}}$} & \multirow[t]{4}{*}{$<0.001 *$} \\
\hline Parenteral & $19(7.9)$ & $223(92.1)$ & 242 & & \\
\hline Inhalation & $0(0.0)$ & $3(100.0)$ & 3 & & \\
\hline Parenteral and Oral & $31(42.5)$ & $42(57.5)$ & 73 & & \\
\hline \multicolumn{6}{|l|}{ Oral switch } \\
\hline Yes & $15(15.0)$ & $85(85.0)$ & 100 & \multirow[t]{2}{*}{12.038} & \multirow[t]{2}{*}{ 0.001* } \\
\hline No & $4(2.8)$ & $138(97.2)$ & 142 & & \\
\hline \multicolumn{6}{|l|}{ Prescribe type } \\
\hline Physician & $53(31.4)$ & $116(68.6)$ & 169 & \multirow[t]{4}{*}{$42.146^{\mathrm{F}}$} & \multirow[t]{4}{*}{$<0.001 *$} \\
\hline Non physician & $18(7.2)$ & $233(92.8)$ & 251 & & \\
\hline Other & $0(0.0)$ & $1(100.0)$ & 1 & & \\
\hline Unknown & $3(14.3)$ & $18(85.7)$ & 21 & & \\
\hline \multicolumn{6}{|l|}{ Parenteral type } \\
\hline Intramuscular & $2(18.2)$ & $9(81.8)$ & 11 & \multirow[t]{3}{*}{$0.739^{\mathrm{F}}$} & \multirow[t]{3}{*}{0.742} \\
\hline Intravenous & $48(16.0)$ & $252(84.0)$ & 300 & & \\
\hline Subcutaneous & $0(0.0)$ & $1(100.0)$ & 1 & & \\
\hline \multicolumn{6}{|c|}{ Guideline compliance } \\
\hline Yes & $42(29.4)$ & $101(70.6)$ & 143 & \multirow[t]{4}{*}{$22.129^{\mathrm{F}}$} & \multirow[t]{4}{*}{$<0.001 *$} \\
\hline No & $1(8.3)$ & $11(91.7)$ & 12 & & \\
\hline Not assessable & $29(11.1)$ & $233(88.9)$ & 262 & & \\
\hline No information & $2(8.0)$ & $23(92.0)$ & 25 & & \\
\hline
\end{tabular}

$\chi^{2}$ : Chi square test; F: Fisher's exact test; *: $p$ value $<0.05$ 


\section{Discussion}

Inappropriate prescription promotes inappropriate use of antibiotics; this has resulted in antibiotics resistance in a community in a developing country. This has increased resistance to first-line antibiotics and promote the use of second-line antibiotics, which has high resistance potential in the community [3]. A total of 891 antibiotics were prescribed in 442 prescriptions. The average number of antibiotics per prescription was approximately 2.0. Of the 442 Prescriptions given to patients, $63.1 \%$ for male while the remaining $36.9 \%$ for females. The mean age of the patients was $33.04 \pm 21$.3SD years.

The most used antibiotics with the highest frequency were Metronidazole (44.6\%), Ceftriaxone 181(41\%) followed by ciprofloxacin 151(34.2\%), while ceftazidime had the least $1(1 \%)$. A similar study carried out in Indian showed that Ceftriaxone 181(41\%) and ciprofloxacin $151(34.2 \%)$ were the highest prescribed antibiotics which were also among the most commonly prescribed in this study [11]. In a study conducted in the University of Nigeria Teaching Hospital, Nigeria, the commonly used antibiotics were Metronidazole and amoxicillin/clavulanic acid [12]. Kamaldeen reported that amoxicillin was the most prescribed antibiotics among the physician in secondary health facilities in Abuja [13]. The pattern of antibiotics prescription might vary from location to location, depending largely on the prevalence of the infection's diseases in the area.

The study also showed that more than $50 \%$ of the antibiotics prescribed are broad-spectrum antibiotics and classify as watch group antibiotics that have higher resistance possibility [14]. They are antibiotics targeted for antibiotic stewardship. The finding in this study showed increasing use of watch group antibiotics (cephalosporin and fluoroquinolone) among hospitalized patients could explain the high rate of resistance to antibiotics among clinical isolates in the Kwara senatorial district. Hence, antimicrobial stewardship intervention is needed to promote the appropriate use of broadspectrum antibiotics in Kwara senatorial district hospital setting.

The average number of antibiotics per prescription was approximately 2.0. Polypharmacy, defined by the World Health Organization as "the administration of many drugs at the same time or the administration of an excessive number of drugs." No agreement on the medication threshold is defining polypharmacy [12]. A study conducted in Sweden in 2009 reported that a multiple of medications less than or equal to 5 as the threshold for polypharmacy [12]. The average number of antibiotics prescribed per prescription in this study was within the acceptable reported rate.

More prescriptions were made in trade name $(57.9 \%)$ compare with a generic name $(42.1 \%)$. This means there is a trend in prescribing antibiotic in their trade name rather than generic names. However, National essential medicines guideline, National drug policy directs prescription of medicines in the generic name [15]. The study conducted among practicing physicians working in tertiary hospitals in four regions of Nigeria reported that $61 \%$ of physicians agreed to prescribe medicines in brand name based on the quality of the information provided by pharmaceutical company [16]. A study in the University of Ilorin Teaching Hospital in Nigeria reported that a minimum $(91.3 \%)$ of the doctors did not prescribe in generic names. The author observed incentives like gifts, samples, and inducements from drug companies as part of promotion strategy by drug companies impact prescription habits of doctors in this teaching hospital [17]. The incentives are given to prescribers to prescribe medicines in trade names by pharmaceutical companies increase the cost of medicines and is substantially promote overuse of antibiotics which promote antibacterial resistance. 
The generic prescription is desired in a developing country like Nigeria as it substantially reduces medicine costs. The Drug Therapeutics Committee, who is responsible for the hospital setting to prepare and implement an appropriate antibiotics policy that will guide antibiotics stewardship implementation, should be strengthen in the hospital to guide against irritational prescription. Prescription in trade name may be attributed to a lack of hospital formulary. A hospital formulary is a periodically revised compilation of essential medicines and health supplies which reflect the commonly available efficacious medicines and health supplied used by healthcare professionals of any institution in line with the regulatory guideline. The hospital should promote the use of hospital formulary to the unethical prescription of medicines in trade name.

Parenteral (54.8\%) was the most reported route of administration, and intravenous was the highest reported parenteral route of administration. This is in contrast with a study in Enugu that reported 26.9\% [18]. The likely reason may be that the study was conducted among in-patient on admission, many of whom may be suffering from life-threatening illnesses which require an injection to produces quick action. The injectable are costly compared with oral dosage form and uses may lead to infection and sepsis. Oral switch if parenteral in this study was relatively below average; about $41.3 \%$ of parenteral were swift to the oral route of administration. The national drug policy encourages the possible oral switch to an oral formulation. Early and timely switch of the parenteral route to oral antibiotics will considerably reduce the expenses incurred by patients and promote rational use of antibiotics.

In this study, only $22.4 \%$ of cases reported receiving antibiotics without justifiable clinical indication for an antibiotic. Antibiotics were given to respondents with a fever of unknown origin. A study conducted in US ambulatory care setting reported $25 \%$ inappropriate indication for antibiotic prescription, and $18 \%$ had no documented indication for antibiotics use [19]. This use of antibiotics for fever of unknown origin and without justifiable clinical reason poses a barrier to antibiotics stewardship and effort to evaluate and improve antibiotics prescription and use.

Community-acquired infection (75.6\%) was the most reported source of infection, and the least reported was hospital-acquired infection $(1 \%)$. Gynaecology and Obstetrics surgery accounted for more than two-thirds (69.2\%) of surgical prophylaxis distantly, followed by GIT surgery with $21.2 \%$. Multiple doses of surgical antibiotic prophylaxis for over 24 hours were more $(69.2 \%)$ reported comparing with multiple doses less than 24 hours (19.2\%) or single-dose prophylaxis $(11.5 \%)$. In a study done in America on clinical practice guidelines for antimicrobial prophylaxis in surgery, the author observed that surgical antibiotic prophylaxis should be discontinued within $24 \mathrm{~h}$ of completion of surgery in most cases [20]. Nevertheless, surgical antibiotics prophylaxis prescription is more than 24hours in this study. This is similar to a study in Nigeria that reported surgical antibiotic prophylaxis was misused [21]. This observation emphasizes a potential target for antimicrobial stewardship intervention.

Overall, the current study highlights the need for the establishment of an antimicrobial stewardship program in Nigerian hospitals considering the high-rate use of watch group of antibiotics with a high rate of potential resistance, long use of surgical prophylaxis, increase prescription in trade name, prescribing antibiotics for unwarranted indications and high empirical treatment type without antibiogram and antibiotics policy in place.

\section{Conclusion}

The high use of antibiotics among in-patient and out-patient in hospitals with watch group of antibiotics with broad spectrum constituting high proportion of antibiotics prescription. These antibiotics are commonly used for community-acquired infection and prolonged 
surgical antibiotic prophylaxis. Metronidazole, ciprofloxacin and ceftriaxone were the most frequently prescribed antibiotics. Antimicrobial stewardship interventions are passionately advocated to reduce the high rate of antibiotic prescription and promote appropriate use of antibiotics in Kwara state hospital. Needed measures should be put in place comprising reorientation and training of physician and other healthcare teams on rational drug prescribing to prevent avoidable expenses on drugs. There is a need for a more sophisticated study that will encapsulate the concerns highlighted above.

\section{References}

[1] Park, J. S., Page, A. T., Kruger, E., \& Tennant, M. (2021). Dispensing Patterns of Medicines Prescribed by Australian Dentists From 2006 to 2018 - a Pharmaco epidemiological Study. In International Dental Journal (Vol. 71, Issue 2, pp. 106-112). https://doi.org/10.1111/idj.12605.

[2] Rolinson GN. (1987). Antibiotic resistance. Vol. 43, Tijdschrift voor Geneeskunde. p. 1233-6.

[3] Costelloe C, Metcalfe C, Lovering A, Mant D, Hay AD. (2010). Effect of antibiotic prescribing in primary care on antimicrobial resistance in individual patients: Systematic review and meta-analysis. Vol. 340, BMJ (Online). p. 1120.

[4] Harbarth S, Theuretzbacher U, Hackett J. (2014). Antibiotic research and development: Business as usual? J Antimicrob Chemother; 70(6):1604-7.

[5] Caminal J, Rovira J. (2005). Antibiotic prescription in primary health care: Clinical and economic perspectives (Catalonia, Spain). Vol. 15, European Journal of Public Health. p. 276-81.

[6] Clarence, Y. S., Edrin, Y. O., \& Odeh EN (2008). Pattern of antibiotic usage by adult populations in the city of Benin, Nigeria. Sci Res Essays, 3(3), 081-085. [7] I.N. O, A. L, R. E. (1999). Socioeconomic and behavioral factors leading to acquired bacterial resistance to antibiotics in developing countries [Internet]. Vol. 5, Emerging Infectious Diseases. p. 18-27. Available from: http://ovidsp.ovid.com/ovidweb.cgi?T=JS\&PAGE=r eference $\& D=$ emed4\&NEWS $=N \& A N=1999096183$.

\section{Acknowledgements}

The author wishes to acknowledge the Heads of Department in the units in all the hospitals. I also wish to thank Dr. Femi Joseph, Dr. Oladipo $\mathrm{O}$, nurses, and medical officers in the wards who assisted in providing clarification on data collection and patient care.

\section{Declaration of Conflicting Interest.}

The Author(s) declare(s) that there is no conflict of interest.

[8] Bebell LM, Muiru AN. (2014) Antibiotic use and emerging resistance: How can resource-limited countries turn the tide? Vol. 9, Global Heart. p. 34758.

[9] World Health Organization (WHO) (2016). WHO, Antimicrobial resistance: global report on surveillance 2014 [Internet]. Antimicrobial resistance: global report on surveillance 2014. Available from: http://www.who.int/drugresistance/documents/survei llancereport/en/\%0Ahttp://www.who.int/drugresista nce/documents/surveillancereport/en/\%0Ahttp://ww w.who.int/antimicrobial-

resistance/publications/surveillancereport/en/\%0Ahtt p://www.who.int/drugresistance/d.

[10] Paterson DL, Rice LB. (2003). Empirical antibiotic choice for the seriously ill patient: Are minimization of selection of resistant organisms and maximization of individual outcome mutually exclusive? Clin Infect Dis; 36(8):1006-12.

[11]Hiremath SRR. (2011). An Official Publication of Association of Pharmaceutical Teachers of India. Indian J Pharm Pract; 4(2):2-3.

[12]R.N. O, C. N, P.O. E. (2019). Antibiotics prescription pattern and determinants of utilization in the national health insurance scheme at a tertiary hospital in Nigeria. Vol. 19, African Health Sciences. p. 2356-64.

[13] Kamaldeen A-S. (2013). Prescription Pattern of Antibiotics among Physicians in a Secondary Health 
Facility in Abuja, Nigeria. Br J Pharm Res.; 3(4):940-7.

[14] Organización Mundial de la Salud. WHO (2019). | WHO releases the 2019 AWaRe Classification Antibiotics [Internet]. Available from: http://www.who.int/medicines/news/2019/WHO_rel eases2019AWaRe_classification_antibiotics/en/.

[15] Nigeria F republic of. The Federal Republic of Nigeria. (2010). [Internet]. Essential drug list. 1-52 p. Available from: http://apps.who.int/medicinedocs/documents/s19018 en/s19018en.pdf.

[16] Joseph O. Fadare, Kazeem A. Oshikoya, Olayinka O. Ogunleye, Olufemi O. Desalu, Alessandra Ferrario, Okezie O. Enwere, Adekunle Adeoti, Taofiki A. Sunmonu, Amos \& brain Massele AB\&. (2018). Drug promotional activities in Nigeria: impact on the prescribing patterns and practices of medical practitioners and the implications. Hosp Pract [Internet]. 46(2). Available from: https://www.tandfonline.com/doi/full/10.1080/2154 8331.2018.1437319?scroll=top\&needAccess $=$ true .
[17] Akande TM, Aderibigbe SA. (2007). Influence of drug promotion on prescribing habits of doctors in a teaching hospital. Afr J Med Med Sci; 36(3):20711.

[18] Margaret N. Aghaji. (2002). Injection practices in Enugu, Nigeria _ International Journal of Medicine and Health Development. Enugu.

[19] Ray MJ, Tallman GB, Bearden DT, Elman MR, McGregor JC. (2019). Antibiotic prescribing without documented indication in ambulatory care clinics: national cross-sectional study. Vol. 367, BMJ (Clinical research ed.). p. 16461.

[20] Bratzler DW, Dellinger EP, Olsen KM, Perl TM, Auwaerter PG, Bolon MK, et al. (2013). Clinical practice guidelines for antimicrobial prophylaxis in surgery. Vol. 14, Surgical Infections. p. 73-156.

[21] Abubakar U, Syed Sulaiman SA, Adesiyun AG. (2018). Utilization of surgical antibiotic prophylaxis for obstetrics and gynaecology surgeries in Northern Nigeria. Vol. 40, International Journal of Clinical Pharmacy. p. 1037-43. 